\title{
Aprendizagem informal: ex-técnicos administrativos x novos gerentes municipais
}

\section{Informal learning: ex-administrative technicians x new municipal managers}

\author{
Adriana Ventola Marra Doutora em Administração. Universidade Federal de Viçosa (UFV) - Brasil. a.ventola.marra@gmail.com \\ Riane Rodrigues Lima Silva Graduada em Administração. Prefeitura Municipal de Contagem - Brasil. rrlimasilva@gmail.com \\ Samara de Menezes Lara Mestre em Administração. Universidade Federal de Viçosa (UFV) - Brasil. mgsamaralara@gmail.com
}

\section{RESUMO}

Objetivou-se neste artigo compreender como técnicos administrativos da administração municipal aprendem a ser gerentes.O referencial teórico foi construído a partir de dois eixos principais: gerente e aprendizagem informal. No aspecto metodológico, utilizou-se uma pesquisa qualitativa descritiva, sendo entrevistados 10 novos gestores de farmácia municipais. A análise de dados se deu por análise de conteúdo, a partir das categorias temáticas propostas por Hill (1993): aprendendo o que significa ser gerente, desenvolvendo o julgamento interpessoal, adquirindo o autoconhecimento, lidando com as tensões e emoções, e gerenciando a transformação. Nos resultados, verificou-se que os novos gerentes aprenderam a função gerencial, principalmente, através do processo de aprendizagem informal. Os seguintes fatores de maior relevância foram observados no processo de aprendizagem informal: experiências anteriores, experiências do dia a dia, reflexão das ações, autoanálise, interação e colaboração em grupo.

Palavras-chave: administração pública; função gerencial; aprendizagem.

\section{ABSTRACT}

The purpose of this article was to understand how administrative technicians of the municipal administration learn to be managers. The theoretical framework was constructed based on two main axes: manager and informal learning. In the methodological aspect, a qualitative descriptive research was used, and 10 new municipal pharmacy managers were interviewed. The analysis of data was based on content analysis, according to the thematic categories proposed by Hill (1993): learning what it means to be a manager, developing interpersonal judgment, acquiring self-knowledge, dealing with tensions and emotions, and managing transformation. In the results, we verified that the new managers developed the managerial skills mainly through the process of informal learning. The following factors of greater relevance were observed in the informal learning process: previous experiences, day-to-day experiences, reflection of actions, self-analysis, interaction and group collaboration.

Keywords: public administration; managerial role; learning. 


\section{INTRODUÇÃO}

Este artigo teve por objetivo investigar como técnicos administrativos da administração municipal aprendem a ser gerentes. Os sujeitos pesquisados foram os novos gestores de farmácia lotados em uma Secretaria Municipal Saúde de Minas Gerais. Para tanto, partiu-se do pressuposto de que a sustentação da carreira gerencial advém da compreensão da interdependência da vida pessoal e profissional, em que o que o gerente aplica no seu cargo, não somente o que aprendeu por meio de qualificação profissional, mas também seus conhecimentos, habilidades e atitudes aprendidas ao longo das experiências vividas nos ambientes familiar, escolar, social e empresarial (Hill, 1993; Hill \& Lineback, 2011; Heikkinen, 2015). Bear et al. (2008) argumentam, neste sentido, que a aprendizagem informal é predominante no ambiente organizacional, servindo para complementar ou substituir a aprendizagem formal das salas de aula. A aprendizagem informal pode ser entendida envolvendo o aprender consigo mesmo, a partir de reflexões sobre seu próprio desempenho; o aprender com os outros, a partir das interações sociais; e o aprender de forma autodidata, por meio de leituras e pesquisas (Noe, Tews \& Michel, 2017).

Tal situação não é diferente para os gerentes do setor público. Quando um técnico se torna gerente, ele passa por um processo longo de construção e aprendizagem, tendo que aprender a lidar com situações técnicas, operacionais, econômicas, sociais, pessoais e/ou emocionais (Davel \& Melo, 2005; Esther, 2007). Vários estudos apontam que o contexto do trabalho, a função exercida e as diferenças individuais influenciam diretamente a aprendizagem informal (Van Noy, James \& Bedley, 2016; Noe, Tews \& Michel, 2016).

Portanto, investigar a aprendizagem informalgerencial, especialmente no âmbito da saúde pública, justifica-se por seu atual contexto de recursos escassos, aspectos burocráticos predominantes, questões legais rígidas, servidores insatisfeitos e população sem atendimento mínimo. Estudos têm demonstrado a exigência de gestores públicos cada vez mais capacitados e dinâmicos, para lidarem com esse cenário (Guerra, Ferreira \& Morais, 2013; Goulart, Leal \& Melo, 2018).

Para tanto, este artigo foi estruturado em cinco itens, incluindo esta introdução. No referencial teórico são abordados aspectos da função gerencial e especificamente no setor público e da aprendizagem gerencial. Posteriormente, são traçados os caminhos metodológicos. A análise e a discussão de dados parteda compreensão do aprendizado do que significa ser gerente, do processo de julgamento interpessoal, do autoconhecimento, do como lidar com as tensões e emoções, e do processo de gerenciamentoda transformação de técnico em gerente. Por fim, são feitas as considerações finais do estudo.

\section{REFERENCIAL TEÓRICO}

As abordagens teóricas que sustentam esta pesquisa se ancoram em dois eixos principais: a gerência na administração pública e a aprendizagem gerencial. No primeiro tópico serão tratados aspectos da administração pública gerencial, da função gerencial e do ser gerente no serviço público. Sobre a aprendizagem gerencial expõem-se as abordagens de aprendizagem formal e informal, e de como os gerentes aprendem especificamente.

\subsection{A administração Pública e o Ser Gerente}

A administração pública burocrática demonstrava sua eficiência no combate à corrupção, à padronização das atividades e ao nepotismo do Estado Liberal, mas no que concerne à prestação de serviços à população nacional, este modelo não se apresentava profícuo. No crescente Estado Social dos anos 1990, do melhoramento da qualidade na execução de ações inerentes ao Estado, especialmente na prestação de serviços sociais de educação e saúde, a administração pública burocrática torna-se ineficaz e inapta a atender as demandas da população. Com isto, torna-se necessária a transição para uma administração pública gerencial (Bresser-Pereira, 1998).

Essa nova gestão pública visa dar ênfase na importância do poder e na mudança de papel dos chamados administradores públicos para gerentes ou gestores públicos profissionalizados, no sentido de que passa a ser desejado um perfil voltado à noção de orientador/integrador e empreendedor, distinto do papel 
de supervisor ou administrador (Junquilho, 2004; Marques, 2011). Na nova gestão pública predominam os valores empresariais, onde há a transformação de atores burocráticos em atores empresariais. Esses valores são voltados às ideias da primazia do cliente e do mercado; da diversidade e flexibilidade; das habilidades multidimensionais dos profissionais; da delegação em lugar do controle; do gerente orientador; da ênfase nos resultados e da educação em vez do treinamento; das estruturas organizacionais enxutas e ágeis (Junquilho, 2004).

A utilização dessas características no âmbito público, para Junquilho (2004), são o que definem a administração pública gerencial. Pode-se afirmar que a função gerencial possui ambiguidades advindas da manutenção de atividades organizacionais e da ruptura de modelos de gestão. No setor público, o acesso ao cargo gerencial se dá comumente por meio de cargos em comissão, não se constituindo como um plano de carreira específico do servidor público estatutário. Nesta ótica, critérios como: competência técnico-científica e trajetória de ascensão profissional na organização tornam-se pouco relevantes no preenchimento de cargos gerenciais. Assim, evidencia-se a não homogeneidade dos ocupantes de função gerencial, pois suas trajetórias e compromissos organizacionais se diferem de acordo com a ausência de uma carreira gerencial (Junquilho \& Melo, 1999). O gestor público é entendido como o responsável pelas atividades de planejamento, organização, liderança e controle de uma organização pública e são responsáveis pela "gestão de recursos escassos, servidores insatisfeitos e desadaptados, burocracia, aparato legal em descompasso com as necessidades presentes e práticas clientelistas e patrimonialistas que emperram o desenvolvimento das instituições em que trabalham." (Marques, 2011, p.94).

Reconhecendo-se que o gestor público trabalha em organizações formais e hierarquizadas ele pode ser classificado pelo nível que ocupa na organização, ou seja, se gerente de primeira linha (primeiro nível), gerente médio ou administrador de topo. O gerente de primeiro nível é aquele gestor responsável apenas pelo trabalho de empregados operacionais, não supervisionando outros administradores. O gerente médio é responsável por outros gerentes e, algumas vezes, por alguns empregados operacionais. Por fim, o administrador de topo é o responsável pela administração global da organização, estabelecendo políticas operacionais na condição da interação organizacional com o seu ambiente (Ckagnazaroff, 2002). Apoiando-se a esse conceito, os sujeitos estudados nesta pesquisa são denominados como gerentes de primeiro nível. Contudo, independentemente de sua posição na hierarquia organizacional os gerentes experimentam conflitos e ambiguidades advindas de sua vivência em universos complexos, não sendo possível identificá-los como grupos homogêneos (Davel \& Melo, 2005).

Os indivíduos com potencial para assumir um cargo gerencial não necessariamente possuem experiências profissionais ligadas à área administrativa, eles podem advir de diversas áreas técnico-específicas, o que demonstra a heterogeneidade deste grupo. Trazendo seu conhecimento singular antes do exercício da gerência, os gerentes são reconhecidos, a partir daí, como profissionais capazes de desenvolver vontades e ações próprias, transitando como agentes passivos e ativos dentro do contexto organizacional (Davel \& Melo, 2005).

Pode-se dizer que o estudo dessa singularidade gerencial inicia-se nos primórdios da administração científica, com Taylor (1966), apesar de não ter sido esse o seu foco, que realizou estudos de racionalização do sistema produtivo, no qual definiu que o gerente deveria planejar e organizar o trabalho, selecionando os trabalhadores adequados para cada tarefa, treinando e controlando o seu desempenho, cabendo ao trabalhador, apenas a sua execução.

Dando continuidade ao estudo do papel do gerente, Fayol (1989) ressalta que o conjunto das operações de toda empresa pode ser dividido em seis grupos essenciais: $1^{\circ}$ ) Operações técnicas: produção, fabricação, transformação; $2^{\circ}$ ) Operações comerciais: compras, vendas, permutas; $3^{\circ}$ ) Operações de segurança: proteção de bens e de pessoas; $4^{\circ}$ ) Operações financeiras: captação e gerenciamento dos recursos financeiros; $\left.5^{\circ}\right)$ Operações de contabilidade: inventários, balanços, preços de custo, estatísticas etc.; 6) Operações administrativas: previsão, organização, direção, coordenação e controle. No qual, ao gerente cabe a responsabilidade de conduzir essas operações para de alcançar os objetivos da organização (Goulart, Leal \& Melo, 2018). 
Propondo outra abordagem, Mintzberg (1986) define que as funções gerenciais vão além do processo administrativo, no qual os gerentes também executam atividades como comunicação com as pessoas e tratamento de assuntos informações com as pessoas subordinadas a eles. Visto por essa ótica, Mintzberg (1986) identificou dez papéis gerenciais, sendo papel, um conjunto organizado de comportamentos que pertencem a uma função ou posição identificável. Os dez papéis foram reunidos em grupos, a saber: papéis interpessoais, papéis de informação, e papéis de decisão. Os papéis interpessoais, advém da autoridade formal, o que envolve a imagem do chefe, do líder e papel do contato. Estes abrangem as relações dentro e fora da organização em que o gerente age como um símbolo e representante da organização. Já os papéis de informação, correspondem à obtenção e transmissão de informações internas e externas da organização, sendo subdivididos entre: monitor; disseminador; e porta-voz. E os papéis de decisão compreendem a resolução de problemas e a tomada de decisões.

Os gerentes, ao assumirem a função gerencial pela primeira vez, enfrentam vários desafios no que tange à gestão dos subordinados, tais como delegar tarefas, cobrar resultados, gerenciar expectativas e conquistar o respeito da equipe, e a confusão entre relações pessoais e profissionais. Para enfrentar tais desafios, estes gerentes mobilizam as experiências on-the-job e as vivências anteriores, bem como os relacionamentos com outros gestores, ex-gestores, amigos, pares ou a própria equipe (Amaral \& Oliveira, 2017). Neste sentido, é relevante compreender como estes novos gerentes aprendem a enfrentar tais desafios.

\subsection{Aprendizagem Gerencial}

Segundo Antonello (2004), a aprendizagem gerencial é um processo dinâmico e ajustado ao meio, é um processo social sobreposto ao contexto organizacional e social, independe de ocorrer em ambientes formais ou informais, nos quais os indivíduos estão inseridos. A questão envolve o indivíduo e como ele aprende no mundo da prática gerencial, ou seja, na situação de trabalho. Cloos e Antonello (2014) apresentam que o processo de aprendizagem gerencial se descreve como o acúmulo e integração de novos saberes, e que pode ser transformador. Para as autoras, aprendizagens para serem consideradas transformadoras não ocorrem de modo individual. Tal processo deve ser de transformação coletiva, compartilhada por outros em meio a mudanças sociais e culturais. Razões e emoções, vida pessoal e vida familiar, são partes essenciais e complementares neste processo de aprendizagem gerencial. Lang, Marinho e Boff (2014) afirmam que na aprendizagem gerencial os sujeitos, em suas ações cotidianas, estão em processo de aprendizagem informal, e a aprendizagem em ação tem como propósito aproximar a realidade diária do profissional com o ensino formal e o desenvolvimento de competências gerenciais. Assim, a troca de experiências e o pensamento reflexivo facilitam a aprendizagem gerencial (Antonello, 2004).

A autora supracitada, buscando identificar e analisar essa aprendizagem formal e informal para o desenvolvimento de competências gerenciais listou as seguintes categorias de aprendizagem: experiência anterior e transferência extraprofissional; experienciar; reflexão; autoanálise; observação de modelos; feedback, mudança de perspectiva; mentoria e tutoria; interação e colaboração em grupo; treinamentos; aprendizagem informal com base na prática e em relacionamentos em cursos de especialização e mestrado; e aprendizagem pela articulação entre teoria e prática. Tais categorias, englobam os processos cognitivos da aprendizagem informal de aprender consigo mesmo, de aprender com os outros, e de aprender de forma autodidata (Noe, Tews \& Michel, 2017).

Estudos apontam que a autonomia do trabalho também é responsável por proporcionar aos indivíduos a oportunidade de aprender, pois lhes dá a oportunidade de buscar a aquisição de conhecimento e de habilidades (Van Noy, James \& Bedley, 2016; Noe, Tews \& Michel, 2017). Assim, a autonomia do trabalho, ou seja, o grau de independência e liberdade que o gerente tem para realizar seu trabalho, influencia positivamente a aprendizagem informal, e, até que ponto os gerentes valorizam e reconhecem a necessidade de aprender, ressaltando as diferenças individuais.

Na busca por respostas de quais competências são desenvolvidas e utilizadas por gestores de origens profissionais distintas, Godoi e D'amelio (2012) identificaram que uma das respostas para essa questão é a aprendizagem de competências gerenciais, sendo um processo contínuo no exercício das atividades dos gestores. Deste modo, as competências profissionais, trazidas de experiências anteriores seria a porta de 
entrada para as competências gerenciais, que surgiriam à medida em que os novos gerentes realizassem as atividades da função gerencial, lidassem com os desafios do cotidiano e fossem se apropriando da nova identidade gerencial. Para Antonello (2004), o desenvolvimento de competências gerenciais acontece a partir dos seguintes elementos: reflexão; diálogo; autodesenvolvimento; aprendizagem experiencial; significado do trabalho; e espaço organizacional de aprendizagem. Ressalta-se a importância da reflexão, pois a capacidade de refletir sobre a experiência precisa ser desenvolvida nos gestores para possibilitar a aprendizagem. Somente a experiência não é suficiente para o aprendizado, pois os indivíduos podem sair com as lições erradas se não refletirem sobre suas experiências (Becker \& Bish, 2017).

Com a preocupação de estudar os aprendizados dos novos gerentes, Hill (1993) realiza estudo seminal descrevendo como os novos gerentes passam de funcionários de nível técnico para gestores de sua equipe e da organização em que estão inseridos. Para Hill (1993) o processo da aprendizagem gerencial está envolvido por cinco dimensões: aprender o que significa ser gerente, desenvolver julgamentos interpessoais, adquirir autoconhecimento, lutar contra tensões e emoções e gerenciar a transformação. Na pesquisa de Hill (1993), as expectativas iniciais dos novos gerentes quanto a sua função eram ligadas à autoridade e responsabilidade de cumprimento da agenda. Ser gerente refletia a figura de "ser o chefe", tomador de decisões, detentor do poder e do controle. Os novos gerentes entendiam que "o foco principal de suas responsabilidades era com as tarefas e não com as pessoas, demonstrando a sua não concordância com a responsabilidade de criar redes". (Hill, 1993, p. 19). No desenvolvimento de julgamentos interpessoais, para Hill (1993), o desafio estava em desenvolver o exercício da autoridade formal concomitante à criação de uma equipe produtiva e satisfeita. Desta forma, ao longo do exercício gerencial, os novos gerentes alinharam as regras e o fluxo logístico, e aprimoraram seu julgamento sobre as questões interpessoais. Quanto a adquirir o autoconhecimento, passaram a perceber que isto demandaria deles não só o aprendizado profissional, como também o aprendizado pessoal, no que cerne a renovação de atitudes e perspectivas psicológicas que o cargo fomenta (Hill, 1993).

Os novos gerentes também aprendem a trabalhar as tensões e emoções de sua nova função. A transformação, o estresse da mudança do cargo, de carreira, das expectativas que tinham deles, e essencialmente a mudança de identidade de técnico para gerente, estão ligadas a essas tensões e emoções vividas pelos novos gerentes. $O$ gerenciamento da transformação se deu através das ações do cotidiano, os processos de tentativa e erro, a observação e interpretação dos fatos conforme sua realidade. Em face disto, a experiência e o aprendizado informal, na opinião dos novos gerentes, é o que de fato os tornaram gerentes. $O$ novo gerente também necessita aprender a gerenciar a si mesmo, sua rede de relacionamentos e seus subordinados(Hill, 1993; Hill \& Lineback, 2011).

Considerando a profundidade e a abrangência dos estudos de Hill (1993), a presente pesquisa foi pautada nestas cinco dimensões. Estudos atuais, como o de Esther (2012) e Santa Bárbara (2012), seguindo a mesma linha metodológica de Hill (1993), apontam que os novos gerentes constroem sua identidade através da transformação psicológica de seu papel e do processo de aprendizagem a partir da experiência. O indivíduo somente se torna gerente a partir do momento que age como tal. Como observou-se nestes estudos, o ser gerente significa agir em torno de suas operações fundamentais: a construção de uma agenda de trabalho e a de uma rede de relacionamento.

Porém, as ações cotidianas dos gerentes são realizadas em ambientes de instabilidade, no qual os conflitos são algo inerentes assuas atividades e a solução destes são de sua responsabilidade (Marra, Freitas, Faria, Lara \& Silva, 2018). No qual ser gerente pode significar coisas diferentes para grupos de indivíduos heterogêneos, pois se os novos gerentes podem emergir de áreas profissionais diversificadas, formando um grupo heterogêneo de novos gestores, as particularidades dos mesmos para a compreensão desse novo cenário podem ser compostas por valores intrínsecos a cada indivíduo somados às experiências pregressas.

A metodologia, próxima parte desta pesquisa, apresentará os caminhos que foram utilizados no intuito de responder aos objetivos desta pesquisa. 


\section{CAMINHOS METODOLÓGICOS}

Esta pesquisa se caracterizou por ser qualitativa e descritiva. O universo da pesquisa de campo foi composto por todos os técnicos administrativos que ocupavam o cargo de gestores de farmácia de uma Secretaria Municipal de Saúde de Minas Gerais. O grupo é formado por 10 novos gestores, sendo 08 do sexo feminino e 02 do sexo masculino, tendo em média 10 meses no exercício da gerência. Os sujeitos participantes compõem a gerência de linha, ou seja, são responsáveis apenas pelo trabalho de empregados operacionais, não supervisionando outros administradores (Ckagnazaroff, 2002).

A coleta de dados desta pesquisa ocorreu por meio de pesquisa documental, observação participante e entrevistas semiestruturadas. Desta forma, realizou-se a triangulação de dados ao utilizar-se de múltiplas fontes de evidência empírica, aumentando a qualidade do estudo ao atribuir-lhe mais rigor, complexidade e profundidade (Yin, 2001; Bruning, Godri \& Takahashi, 2018). Na pesquisa documental, foram utilizados, neste estudo, dos arquivos públicos da Secretaria Municipal de Saúde, o Diário Oficial da cidade; e Matérias Jornalísticas do site oficial da Prefeitura. De acordo com Yin (2001), a observação participante consiste na participação real do conhecimento na vida da comunidade, do grupo ou da situação determinada. $O$ observador assume, até certo ponto, o papel de um membro do grupo. Por este ponto, a observação participante torna-se interessante enquanto método nesta pesquisa, pois uma das autoras trabalhava na Secretaria Municipal de Saúde juntamente com os entrevistados e realizou anotações em diário de campo, durante o período da pesquisa. O diário de campo (caderno) foi constituído a partir de registros das observações da pesquisadora realizadas durante e após as entrevistas e a reconstrução de conversas informais que aconteceram no cotidiano do trabalho na secretaria (Creswell, 2007).

Foram realizadas 10 entrevistas, durante dois meses, com tempo médio de duração de 40 minutos. Em que 4 dos 10 novos gerentes foram entrevistados em suas respectivas residências, 3 foram entrevistados dentro da Secretaria de Saúde e 3 foram entrevistados em pontos de encontro diferentes. $\mathrm{O}$ acesso com os entrevistados foi facilitado por uma das pesquisadoras já trabalhar com eles. Isso também proporcionou aos entrevistados uma tranquilidade ao responder as questões do roteiro e dialogar mais abertamente sobre as vivências de seu cotidiano.

Utilizou-se a entrevista semiestruturada com o objetivo principal de compreender os significados que os entrevistados atribuem às questões relativas ao objeto de estudo. Possibilitando ao pesquisador perceber os fatos na linguagem do próprio sujeito, o que possibilita ao pesquisador, a identificação da forma como os sujeitos interpretam os aspectos do mundo (Godoi, 2006).

A análise de dados se deu por análise de conteúdo (Bardin, 2010), a partir das categorias temáticas propostas por Hill (1993), estabelecidas a priori, a saber: aprendendo o que significa ser gerente, desenvolvendo o julgamento interpessoal, adquirindo o autoconhecimento, lidando com as tensões e emoções, e gerenciando a transformação. A análise de conteúdo perpassou pelas três fases, preconizadas por Bardin (2010): 1) pré-análise, 2) exploração do material e 3) tratamento dos resultados, inferência e interpretação. Na pré-análise, o material (entrevistas, diário de campo e documentos) a ser analisado foi organizado, foi feita uma leitura flutuante e a delimitação do que seria analisado. Na segunda fase, a exploração do material foi realizada a codificação do material, com numeração das entrevistas de G1 a G10, e a identificação das unidades de registro (segmentos de conteúdo nos documentos, entrevistas e diários de campo) a partir das categorias de temáticas de Hill (1993). Na inferência e interpretação, terceira fase, foi realizada a condensação das unidades de registro, buscando as informações para a análise e interpretações inferenciais (Bardin, 2010).

\section{RESULTADOS E DISCUSSÕES}

O cargo gestor de farmácia foi criado em 2015 pela Secretaria Municipal de Saúde. Os gestores iniciaram o exercício dessa função em março de 2015 , mas somente em junho do mesmo ano, foi instituída a Portaria 7.115 (2015), que criou a comissão de gestão de farmácias, formalizando o cargo e suas funções, como é evidenciado em ser artigo terceiro.

Art. $3^{\circ}$ Compete aos servidores membros do Comitê Municipal de Gestores das Farmácias Distritais, em suas respectivas lotações:[...] 
II - coordenar e supervisionar as atividades e serviços realizados na Farmácia Distrital

[...] V - gerenciar o cumprimento das escalas de trabalho bem como da jornada de trabalho dos profissionais da Farmácia Distrital

[...] IX - obter informações precisas, junto às áreas competentes, acerca da falta de medicamentos, para o encaminhamento do usuário de forma adequada;

$\mathrm{X}$ - ter conhecimento do trâmite administrativo de fornecimento de medicamentos pelas Farmácias Distritais;

$\mathrm{XI}$ - controlar o estoque de medicamentos e insumos necessários para o funcionamento da farmácia, a fim de que seja realizado o devido abastecimento dos itens [...] .

Os novos gestores de farmácia foram convidados por suas chefias imediatas, para assumirem o cargo de Gestão de Farmácia. Esse convite partiu de uma escolha subjetiva das diretorias, onde foi avaliado através de sua trajetória profissional no serviço público e sua contribuição para o setor se ele possuía perfil para assumir a função (Anotações do diário de campo).

O gerente é um símbolo da organização, ou seja, a partir do momento que ele assume a gerência, sua imagem fica diretamente atrelada à instituição (Mintzberg, 1986). Ser a representação de algo ocasiona na transferência de responsabilidades que esse símbolo representa. A pressão que o gestor possui ao se tornar o símbolo de uma organização, inicialmente, advém da necessidade de ele suprir as expectativas de seus subordinados e de seus superiores no exercício de suas atividades. Pode-se perceber no relato de G1 que esse evento ocorre de modo automático após assumirem o cargo. Não é preciso que o gerente tome nenhuma decisão para que ele já seja visto pela equipe que irá coordenar, que ele é a representação mais próxima da instituição dentro do setor.

Eu até assustei, quando cheguei no outro dia para trabalhar, todos já sabiam que eu seria a gestora da farmácia e já me trataram diferente, como tratam a chefe, a diretora do distrito. (G1)

Os gerentes ao assumirem o cargo se depararam com situações que terão que agir, mesmo sem saber como resolvê-las, para tanto irão utilizar de suas bagagens anteriores, ou seja, de conhecimentos formais e informais adquiridos ao longo de sua vida (Hill, 1993; Marra et al., 2018). No depoimento de G4, nota-se que esta pressão ocorre nas primeiras percepções do exercício da gerência, pois o gestor ainda não consegue compreender como ele atenderá a essas expectativas.

O pessoal dizia, "ah, isso quem tem que resolver é a chefe", mas eu não tinha a mínima ideia de como resolver. [...] Mas aí de um jeito ou de outro eu acabava resolvendo, às vezes sem nem perceber eu já tinha resolvido. (G4)

Hoje entendo que ser gerente é assumir as responsabilidades do setor e tentar solucionar os problemas da melhor forma possível, mas no início eu achava que eu só ia assinar as folhas de ponto, ter que comparecer nas reuniões de colegiado que eu já estava sendo gerente, hoje eu vejo que 'o buraco é bem mais embaixo'. (G9).

O relato da entrevistada G9, além de demonstrar a questão de o gerente ser gerente antes mesmo de compreender o que significa isso, aponta também para a questão do cumprimento de agenda do gerente. Esse fato coincide com os resultados obtidos no estudo de Hill (1993), pois nele foi percebido que as expectativas iniciais dos gerentes estavam relacionadas à autoridade e responsabilidade de cumprimento de agenda. Ao dizer que para ela, ser gerente era apenas assinar folhas de ponto e comparecer às reuniões de colegiado gestor, G9 demonstra que inicialmente ela não se preocupava com a gestão das pessoas, e sim no foco à suas tarefas. As anotações no diário de campo também indicam essa expectativa inicial se contrapondo com a realidade já vivenciada de ser gerente.

Também se pôde inferir por Closs e Antonello (2014) que o equilíbrio entre vida pessoal, familiar e profissional se torna crucial para minimizar os conflitos pessoais vividos pelo novo gestor na aprendizagem gerencial. Esse aspecto, comum aos relatos de 6 entrevistados, pode ser observado no extrato abaixo, onde o 
novo gestor demonstra ter passado e ainda passar por dificuldades de equilibrar a vida profissional com a vida pessoal e familiar.

Meu marido que fica bravo, diz que depois que virei chefe eu só sei falar de serviço, que tudo que nós conversamos tem alguma coisa a ver com as coisas que acontecem na farmácia. Eu faço sem pensar, [...] no início até jantando eu pensava em como resolver alguma situação [...] (G3).

As conversas informais sobre como conseguir equilibrar família e trabalho dominavam os corredores da secretaria (anotações do diário de campo). Contudo, temos outros quatro entrevistados que disseram que conseguem equilibrar a vida pessoal com a profissional. Conforme o extrato da entrevista abaixo, eles evitam tratar de assuntos do local de trabalho em casa e tentam manter as atividades familiares constantes.

Eu não gosto de falar de serviço quando eu chego em casa, eu tento ao máximo deixar todos os problemas da farmácia na farmácia, e só quando eu chegar no outro dia pra trabalhar eu penso no que tenho que resolver.[...] (G5).

Após as impressões iniciais de como será o exercício da função gerencial, o novo gerente agora precisa lidar com as relações interpessoais da nova função, mudar a percepção sobre si e começar a agir como gerente. Conforme Hill (1993) e Goulart et al. (2018) no desenvolvimento de julgamentos interpessoais, o desafio está em desenvolver a autoridade formal à criação de uma equipe produtiva e satisfeita, no qual se faz necessário saber lidar e se envolver com os indivíduos da organização. Como essa situação era algo que os gerentes não estavam acostumados a lidar, tiveram que aprender na prática do exercício gerencial como delegar e controlar tarefas e desenvolver o comprometimento da equipe. Uma das atitudes que um dos novos gerentes entrevistados utilizou foi fazer uma reunião de equipe assim que assumiu o cargo para conhecer todos e a atividade que cada um exercia e, ao longo dos dias, ele foi conversando isoladamente com cada servidor, a fim de conhecer melhor o perfil de cada um.

Eu fiz uma reunião assim que fui pra farmácia, para conhecer o pessoal, as novas diretoras sempre fazem isso quando chegam ao distrito, e eu percebia que isso quebrava o gelo com a equipe [...] Eu falei um pouco sobre mim e perguntei o nome e o que cada um deles fazia na farmácia [...] Durante o dia eu ia conversando com eles separado, assim eu conseguia conhecê-los melhor e a opinião deles sobre a situação do setor e o compromisso deles. (G5)

A abordagem de outro novo gerente, para alcançar uma equipe comprometida e receptível a ele, foi de enfatizar sempre que possível que ele era parte da equipe, e não queria ser visto como um membro superior aos outros.

Eu sempre digo pros meninos, eu não sou maior, ou melhor, eu eles, eu sou parte da equipe, eu estou lá para somar. Eu digo isso pra eles não me verem como alguém que tá vigiando o que eles fazem, para eles me aceitar com mais facilidade. (G3)

A rigidez da estrutura burocrática (Junquilho \& Melo, 1999), muito presente ainda nas organizações públicas, desafia o novo gerente a seguir padrões e normas da instituição, concomitante ao gerenciamento de processos e pessoas. O depoimento da entrevistada G6 exemplifica a sua posição e de outros sete entrevistados que apresentaram posição semelhante de que o padrão burocrático, utilizado para a aquisição de insumos, principalmente de medicamentos, impacta no exercício da gerência, pois os processos de solicitação de compra possuem etapas morosas onde neste período, o novo gerente deve lidar com a cobrança da população que aguarda a medicação em falta, a expectativa de sua chefia dele ser capaz de administrar na adversidade e a autocobrança em atender as expectativas dos dois lados.

Eu sempre ouvia dizer que o processo para solicitar material era bem demorado, mas eu pensava que se eu preenchesse todos os pedidos com bastante antecedência não haveria esse problema [...] Eu me 
sinto muito mal, quando chega um idoso na farmacinha e não tem a medicação que ele necessita, eu me sinto culpada (G6).

Por outro lado, dois novos gerentes entrevistados, disseram que, em algumas situações, a burocracia pode auxiliar nas atividades mais mecânicas função gerencial. E de certa forma, a partir das anotações do diário de campo, percebeu-se que esses gerentes se sentem protegidos pela burocracia, pois esta os desonera de algumas decisões "difíceis" em que afirmam, "estamos só cumprindo as leis". Ressalta-se que a palavra "burocracia" foi utilizada pelos entrevistados para fazer inferência linguística às funções legais exigidas na função gerencial e, não tem o sentido do modelo ideal da burocracia weberiana.

Nossa, se eu tivesse que preencher aquele tanto de formulário sem seguir os padrões eu ia ter muito mais trabalho, [...] desse jeito eu faço uma ou duas vezes e o restante fica fácil, quase automático. (G2). Mesmo tendo muito "detalhezinho", uma norma para cada documento, eu prefiro assim, porque aí fica mais difícil de eu cometer algum erro mais grave. (G5)

Depois de lidar com o julgamento interpessoal, o novo gerente passa analisar suas forças e deficiências, a fim de adquirir autoconhecimento, necessário para se compreender como pessoas e como gestores. No caso estudado, os novos gerentes de primeiro nível, assumem a responsabilidade não mais apenas de sua atividade individual, mas também é responsável pela coordenação e supervisão de uma farmácia distrital. Os novos gerentes foram assimilando essas responsabilidades nas práticas do cotidiano, a cada evento novo, o gerente teve o desafio de assimilar o que é de sua competência ou não. No extrato da entrevista de G2, pode-se notar como o novo gerente começa a tomar consciência de suas novas responsabilidades.

Com a redução da carga horária semanal dos assistentes administrativos de 40 para 30 horas, eles iriam trabalhar 6 horas diárias e então deveriam escolher se trabalhariam na parte da manhã ou à tarde [...] Mas ai tinha duas servidoras que não entravam em acordo de jeito nenhum de quem iria trabalhar em qual horário, e de repente elas a querer que eu resolvesse a situação. [...] Demorou a cair minha ficha de que agora eu tinha que resolver essas e várias ouras picuinhas entre os servidores da farmácia. (G2).

Para o novo gerente, segundo Hill (1993), ser gerente refletia à figura de "ser o chefe", tomador de decisões, detentor do controle e do poder. Evidencia-se esse fato no depoimento do novo gerente que revela gostar de ser gerente por ter o poder de mudar as coisas, controlar os processos e tomar as decisões a partir das informações recolhidas pelas facilidades vindas com o cargo.

Poder mudar as coisas que eu via que não dava certo antes é uma parte muito boa de ser gerente, eu gosto por isso [...\} Esse poder, mesmo que pequeno, me faz ter um controle maior das coisas, eu consigo ter informações mais fácil e controlar como elas chegaram ao pessoal da equipe. (G4)

Após adquirir o autoconhecimento, o novo gerente aprende a lutar com as tensões e gerenciar as emoções inerentes ao cargo. As tensões estão ligadas à transformação do novo gerente, à mudança de sua identidade profissional. Segundo Hill (1993), os novos gerentes, no percurso da construção de sua identidade gerencial, aprendem a trabalhar as tensões e emoções de sua nova função. As tensões do cotidiano são apontadas por Davel e Melo (2005) como ambíguas e conflituosas e novos gerentes enfrentarão as tensões a partir das experiências cotidianas. No extrato da entrevista de G5, o novo gerente demonstra que a maior tensão que ele enfrenta é na administração de pessoas.

É complicado administrar o pessoal, porque cada um pensa e age de um jeito e às vezes eles são muito resistentes [...] Eu me estresso muito quando o servidor diz entender a forma que eu orientei para fazer alguma atividade e na hora de fazer, ele faz completamente diferente. (G5). 
O volume de trabalho e a complexidade das tarefas também é um fator de tensão na função gerencial. Isso pode ser demonstrado como um dificultador do exercício da gerência através do depoimento de G8, onde o novo gerente mostra que ele cumpre várias tarefas e muitas não são semelhantes e demandam tempos diferentes. A partir das anotações do diário de campo, ressalta-se que todos os entrevistados, ao final das entrevistas, reclamaram do volume de trabalho e da sensação de terminar o dia "sempre devendo alguma tarefa que deveria ser feita".

Nossa, eu não paro nem um minuto, como são muitas coisas para resolver eu tenho que fazer ao mesmo tempo, mas aí eu não consigo acabar com uma coisa para fazer a outra, isso acaba demorando mais ainda e piorando a situação. (G8).

Outro ponto que causa dificuldades para o exercício da gerência são os subordinados problemáticos. Esse caso foi identificado no extrato da entrevista de G8, onde o novo gerente aponta que um servidor resistente às ordens e suscita conflitos na equipe pode tornar-se um grande motivo de tensão no exercício da gerência.

Pra mim, a pior coisa é aquele servidor que não colabora com a equipe e ainda causa desconforto para os outros funcionários. (G8)

Quando a relação do novo gerente com a sua equipe é uma relação de proatividade e interesse no bem comum. Isso se apresenta como um ponto facilitador no exercício da gerência podendo ser verificado no relato de G1, onde o novo gerente aponta que se a equipe segue a mesma linha de ações do gerente, as relações se tornam mais fáceis e os resultados mais evidentes.

O que facilita meu trabalho é quando minha equipe está bem alinhada comigo, quando eles fazem conforme foi definido, quando eu não preciso ficar cuidado de demandas que eles mesmos podem resolver [...]. (G1)

Outro ponto facilitador é quando o novo gerente se sente respaldado pelo seu superior. Ao tomar suas decisões, em concordância com as orientações de seu superior, que demonstra depositar confiança em sua gestão, o novo gerente se sente mais confortável em manter e defender suas ações.

Eu me sinto mais seguro quando converso com minha chefia imediata e ela me passa confiança, diz que está vendo meu empenho e apoia minhas decisões. (G3).

Ao lidar com tensões e emoções, o novo gerente começa a gerenciar a sua transformação para gerente, o que ocorre a partir das formas de aprendizagem que o levaram á essa mudança. Na busca por analisar e identificar a aprendizagem gerencial e formal, utilizou-se categorias: experiência anterior e transferência extraprofissional; experienciar; reflexão; autoanálise; aprendizagem informal com base na prática e aprendizagem pela articulação entre teoria e prática descritas por Antonello (2004).

Os novos gerentes utilizam-se de experiências e aprendizagens anteriores como facilitadores para agir como gerentes. Esse fato pode ser percebido no depoimento dos entrevistados, onde relatam que o conhecimento prévio do setor e da organização serviu como apoio para exercer e aprender a função gerencial.

Como eu já conhecia praticamente todo mundo [...] , isso me ajudou a ter mais abertura para conversar com a equipe, porque eles sabiam que eu conhecia muito da rotina do setor. (G7).

O experienciar, como dito por Antonello (2004), pode ser percebido na fala do novo gerente G2, onde ele aponta que aprende a cada dia como gerenciar, para ele o exercício da gerência é um aprendizado diário. Assim como G2, para todos os demais gestores a forma como ordenar, como controlar e como se comunicar vai sei moldando à medida que se vivência a função. 
Todo dia eu aprendo um pouco como ser gestor, porque eu vou aprendendo com minhas próprias atitudes [...]se as pessoas não aceitaram o jeito que fiz uma coisa eu tento mudar também, eu vou adaptando pra eu me sentir bem nas minhas decisões. (G2).

O depoimento anterior de G2 também apresenta o fator reflexão. Para Closs e Antonello (2014) e Becker e Bish (2017) a reflexão é parte importante do processo da aprendizagem transformadora. É na aprendizagem informal que a reflexão das experiências resulta em conhecimento para o novo gerente. A autoanálise deve ser feita pelo novo gerente para que ele possa perceber como está se sentindo nessa nova posição profissional. As tensões e os desafios no exercício da gerência são vivenciados de forma diversa por cada sujeito, e somente o novo gerente pode externalizar como se sente nessa transformação. Os novos gerentes foram questionados sobre o que para eles era ser gerente e suas respostas demonstraram ao mesmo tempo a sua autoanálise de como se sentiam como gerentes.

A autoanálise deve ser feita pelo novo gerente para que ele possa perceber como está se sentido nessa nova posição profissional. As tensões e os desafios no exercício da gerência são absorvidas por cada sujeito de uma forma diferente, e somente o novo gerente pode demonstrar como se sente nessa transformação. Os novos gerentes foram questionados sobre o que para eles era ser gerente e suas respostas demonstraram ao mesmo tempo a sua autoanálise de como se sentiam como gerentes.

Ser gerente para mim saber a melhor forma de conduzir a equipe, tomar as decisões mais corretas para cada situação e ser um exemplo dentro para a equipe (G1).

Ser gerente é controlar tudo, saber como tudo acontece e orientar para que aconteça da forma que você precisa que aconteça (G2).

Ser gerente é saber lidar com os problemas do setor e resolve-los da melhor forma possível, é assumir as responsabilidades (G3).

Ser gerente é ser o porta-voz dos superiores, e cuidar tanto das questões administrativas quanto do relacionamento dos servidores dentro do setor (G4).

Ser gerente é um aprendizado, uma nova experiência profissional (G5).

Ser gerente é ajudar a melhorar o atendimento aos usuários da farmácia, organizando a equipe e controlando os processos administrativos (G6).

Ser gerente é ser responsável por tudo que ocorre no setor e representar esse setor dentro da Secretaria (G7).

Ser gerente é organizar a equipe, organizar o modo como as coisas serão feitas e passar aos superiores como esta o andamento do serviço (G8).

Ser gerente é administrar o setor, controlar o estoque, solicitar insumos, responder às demandas $\mathrm{e}$ organizar a equipe (G9).

Ser gerente é saber lidar com as várias personalidades dentro do setor, fazer as pessoas entrarem em acordo e controlar as questões administrativas (G10).

De acordo com o site oficial da Prefeitura, todos os entrevistados passaram por um treinamento na Secretaria de Saúde. O objetivo do treinamento era mostrar aos gestores a importância de melhorar a qualidade do atendimento ao usuário e de fortalecer as farmácias distritais. Todos deixaram explícita a importância do treinamento, principalmente para o aprendizado gerencial (anotações do diário de campo). Isso auxiliou os novos gerentes a mensurar a importância de seu cargo dentro da Secretaria. Outra consequência foi a interação e colaboração em grupo, pois a partir desse encontro, os novos gerentes continuaram o contato entre si, compartilhando aprendizados e fortalecendo o grupo.

É muito bom dividir os problemas que eu passo com outros gestores, quando eu tenho alguma dúvida eu ligo pro G2 ou pra G6 para trocarmos experiências. (G3).

Somente um dos entrevistados possui curso superior na área de saúde, e relata que a sua graduação o auxilia no controle de medicamentos. Mesmo com essa variação de qualificação, os novos gerentes relatam a fala comum de que o gerenciamento da transformação se dá pela aprendizagem prática, pelas dificuldades e superações que os novos gerentes vivenciam no cotidiano gerencial como forma de aprendizagem informal. 


\section{CONCLUSÕES}

O objetivo deste artigo foi investigar como técnicos administrativos da administração municipal aprendem a ser gerentes. Os sujeitos pesquisados foram os novos gestores de farmácia lotados em uma Secretaria Municipal Saúde de Minas Gerais. A investigação da aprendizagem gerencial dos novos gerentes foi suportada pela revisão de literatura, tendo sido ancorada por dois eixos principais: a administração pública e o ser gerente; e a aprendizagem gerencial. O cargo gestor de farmácia foi criado pela gestão 2013-2016 da Secretaria de Saúde pesquisada. Foram realizadas entrevistas com os 10 novos gestores de farmácia. A partir da análise dos dados observou-se que os novos gestores de farmácia entrevistados aprenderam o que significa ser gerente antes mesmo de se tornarem gerentes de fato. Isso ocorreu nas primeiras impressões que eles tiveram de si após a nomeação. Os novos gerentes foram vistos rapidamente como símbolo da organização. Contudo, alguns passaram a se preocupar, inicialmente, mais com o cumprimento de agenda e tarefas do que com o gerenciamento de pessoas.

No julgamento do desenvolvimento interpessoal, o principal desafio foi desenvolver autoridade formal para criação de uma equipe produtiva e satisfeita. Nessa fase, observou-se que os gestores tentaram realizar reuniões e dialogar com sua equipe para conquistar o comprometimento da mesma. Para alguns novos gerentes, a burocracia apresentou-se como um desafio, pois as normas e padrões estabelecidos dificultaram o andamento dos processos. Por outro lado, outros entrevistados viram a burocracia como um facilitador da ação gerencial, como por exemplo, no preenchimento dos formulários. Outro desafio para os novos gerentes foi superar as expectativas de seus superiores onde eles esperam que os gerentes saibam lidar com as adversidades minimizando os impactos negativos.

Ao assumir a função gerencial, os novos gerentes deixaram de ser responsáveis apenas por sua atividade individual e passaram a ser responsáveis pela coordenação e supervisão do setor. Observou-se que para lidar com os conflitos e adversidades da função gerencial os novos gerentes passaram a assimilar suas responsabilidades nas práticas do cotidiano passando a entender e conhecer que todos os processos administrativos e de organização dependem de suas ações como gerente. Percebeu-se também que os novos gerentes absorveram a questão do poder vinculado ao seu cargo como um agente facilitador na obtenção de informações e controle de seus subordinados.

Lidando com as tensões emoções, os novos gerentes perceberam o desafio de lidar com as tensões do cotidiano pertinentes à nova função. Os novos gerentes analisados destacaram a gestão de pessoas e o volume de trabalho como os maiores pontos de ambiguidade e conflito. Eles lidam com estes desafios a partir das experiências cotidianas e vão adequando o seu ritmo de trabalho e a forma de gerenciar as pessoas de acordo com os resultados obtidos. No gerenciamento da transformação os novos gerentes tiveram o desafio de entender o que é ser gerente e como foi o seu processo de aprendizagem. Deste modo, conclui-se que ser gerente para os entrevistados significou assumir as responsabilidades do setor através do controle e melhoria dos serviços prestados à população, gerir pessoas, compreendendo o perfil de cada subordinado e equilibrando o desempenho da equipe, lutar pelo resultado das decisões tomadas e alcançar a confiança de seus superiores.

Deste modo os novos gerentes aprenderam e continuam aprendendo a ser gerentes a partir do processo de aprendizagem informal. As experiências do cotidiano nas atividades realizadas na prática configuraram a transformação do servidor operacional para novo gerente. Conforme relatos dos novos gerentes entrevistados, os que possuíam algum curso ou graduação apontaram que esse conhecimento não foi essencial para o desenvolvimento da gerência, eles auxiliaram em algumas atividades marginais. Observaram-se os seguintes fatores de maior relevância no processo de aprendizagem: através de experiências anteriores, experiências do dia a dia, da reflexão das ações, da autoanálise da interação e da colaboração em grupo.

Os resultados demonstraram que, embora os gerentes pesquisados valorizem e atribuam a maioria de seu aprendizado a meios informais, ressalta-se que os gerentes não descartaram totalmente os modos formais de aprendizagem, e expressaram o desejo por eles. Assim, defende-se que, por ser predominante, a aprendizagem informal dos gestores públicos deve ser valorizada e adotada como uma estratégia deliberada 
pela administração pública concomitantemente aos modos formais de aprendizagem. Neste sentido, considera-se que a aprendizagem informal e a formal não estão em polos opostos e nem são excludentes, são complementares, podendo-se aproveitar os benefícios de cada modo.

Sugere-se para estudos futuros que se pesquise esta problemática levando em consideração uma amostra constituída por novos gestores de nível intermediário e nível superior na administração pública, a fim de compreender como se configura o processo de aprendizagem nesses grupos. Sugere-se também que se estude técnicos administrativos que deixaram a função gerencial com a troca dos prefeitos, e que voltaram a desenvolver as atividades de ordem técnica. Entende-se como contribuição desta pesquisa o estudo de alguns aspectos importantes para o treinamento e preparação de novos gerentes para o setor público. Como limitações desta pesquisa, destacam-se aquelas inerentes ao estudo de caso, pois as conclusões apresentadas representam apenas a realidades dos novos gestores de farmácia, e o fato de a pesquisa ter sido realizada apenas com os novos gerentes, sem investigar as percepções de seus superiores e subordinados. Acrescentam-se a tais limitações, o fato de uma das pesquisadoras trabalhar no mesmo local dos gerentes pesquisados, o que apesar de facilitar a interação pesquisador e pesquisados, estes últimos podem ter se sentido constrangidos de relatar tudo o que pensam a alguém que trabalha com eles.

\section{REFERÊNCIAS}

Amaral, R. C. G., \& Oliveira, L. B. (2017). Os Desafios da Primeira Gestão: Uma Pesquisa com Jovens Gestores. Revista de Administração Contemporânea, 21(3), 373-392.

Antonello, C. (2004). Alternativas de Articulação Entre Programas de Formação Gerencial e as Práticas de Trabalho: uma contribuição no Desenvolvimento de Competências(Tese de doutorado). Escola de Administração - Universidade Federal do Rio Grande do Sul, Porto Alegre, RS, Brasil.

Bardin, L. (2010). Análise de conteúdo Lisboa: Edições 70.

Bear, D. J., Tompson, H. B., Morrison, C. L., Vickers, M., Paradise, A., Czarnowsky, M., Soyars, M. and King, K. (2008), Tapping the Potential of Informal Learning. An ASTD Research Study (Alexandria, VA: American Society for Training and Development).

Becker, K. \& Bish, A. (2017) Management development experiences and expectations: informal vs formal learning, Education + Training, 59(6), 565-578.

Bresser-Pereira, L. C. (1998). A reforma do estado dos anos 90: lógica e mecanismos de controle. Lua Nova: Revista de Cultura e Política, (45), 49-95.

Bruning, C., Godri, L., \& Takahashi, A. R. W. (2018). Triangulação em Estudos de Caso: Incidência, Apropriações e Mal-Entendidos em Pesquisas da Área de Administração. Administração: Ensino e Pesquisa, 19(2), 277307.

Ckagnazaroff, I. B. (2002, outubro). Reforma gerencial e o papel do gestor público: ator de mudança ou de resistência? VII Congreso Internacional del CLAD sobre la Reforma del Estado y de La Administración Pública, Lisboa, Portugal.

Closs, L., \& Antonello, C. (2014). Aprendizagem de Gestores no Contexto das Transformações Contemporâneas no Mundo do Trabalho. Revista de Ciências da Administração, 0, 149 - 163.

Creswell, J. W. (2007). Projeto de pesquisa: métodos qualitativos, quantitativos e mistos. (2a . ed.) Porto Alegre: Artmed.

Davel, E., Melo, M., (2005).Singularidades e transformações no trabalho dos gerentes.In E. Davel \& M. C.O.L.Melo (Orgs.), Gerência em Ação (1 aed.,pp. 29-66). Rio de Janeiro: Editora FGV.

Esthér, A. B. (2007).A construção da identidade gerencial dos gestores da alta administração das Universidades Federais em Minas Gerais.(Tese de doutorado).Faculdade de Ciências Econômicas Universidade Federal de Minas Gerais, Belo Horizonte, MG,Brasil. 
Esther, A. B. (2012). "A primeira vez a gente nunca esquece": a experiência subjetiva de se tornar gerente pela primeira vez. Abet, $\mathrm{XI}(2), 112-132$.

Fayol, H. (1989).Administração Industrial e Geral. São Paulo: Atlas.

Godoi,C. K., Melo,R. B., Silva,A. B. (Org.) (2006). Pesquisa qualitativa em estudos organizacionais: paradigmas, estratégias e métodos. São Paulo: Saraiva.

Godoy, A. S., \& D’amelio, M. (2012). Competências gerenciais desenvolvidas por profissionais de diferentes formações. Organizações \& Sociedade, 19(63), 621-639.

Goulart, A., Leal, R., \& Melo, M. (2018). Passado e presente do conceito da função gerencial: uma análise geracional com mulheres gerentes. Revista Gestão \& Tecnologia, 18(3), 205-224.

Hill, L. A. (1993). Novos gerentes: assumindo a nova identidade. São Paulo: Makron.

Hill, L. A., \& Lineback, K. (2011). Being the boss. Boston: Harvard Business School Press.

Junquilho, G. S.(2004). Nem "burocrata" nem "novo gerente": o "caboclo" e os desafios do Plano Diretor de Reforma do Estado no Brasil do real. Revista de Administração Pública, 38(1), 137-156.

Junquilho, G.S.,\& Melo, M.C.O.L.(1999, setembro). Traços caboclos, gestão e trabalho gerencial no setor público brasileiro: problematização, evidências e proposta de análise. In: XXIII Encontro da Associação Nacional dos Programas de Pós-Graduação em Administração, Foz do lguaçu, RS, Brasil, XXIII.

Heikkinen, S. (2015).Significant Others: The Role of the Spousse in Women and Men Managers Careers in Finland. (Dissertação de Mestrado).Jyvaskylan Y liopisto, Jyvaskyla, Finlândia.

Lang, J.; Marinho, S. V.; Boff, M. L. (2014) Aprendizagem em ação, competências e a relação com a aprendizagem gerencial. Revista Pretexto, 15 (ne), 67-83.

Marques, A. L. (2011). Gerentes em organizações públicas: características do trabalho e contexto profissional. Gerais: Revista Interinstitucional de Psicologia, 4(1), 93-103.

Marra, A. V., Freitas, L. M., Faria, J.C.,Lara, S. M., Silva, D. H. Identidade gerencial dos prefeitos: um estudo a partir das práticas discursivas. Revista ADM.MADE,22(3), 22-37.

Mintzberg, H. (1986). Trabalho do executivo: o folclore e o fato.São Paulo: Nova Cultural.

Noe, R. A., Tews, M. J. and Michel, J. W. (2017), Managers' informal learning: a trait activation theory perspective. International Journal of Training and Development, 21: 1-17.

Portaria n. 7.115, de 11 de junho de 2015(2015). Cria, no âmbito da Fundação de Assistência Médica e de Urgência de Contagem - FAMUC, o Comitê Municipal de Gestores das Farmácias Distritais, e estabelece normas gerais e procedimentos para o processamento da Gestão das Farmácias Distritais. Diário Oficial de Contagem - Edição 3643. Contagem, MG.

Taylor, F.W. (1966). Princípios de Administração Científica. São Paulo: Atlas.

Van Noy, M., James, H. and Bedley, C. (2016), Reconceptualizing Learning: A Review of the Literature on Informal Learning (Piscataway, NJ: Education and Employment Research Center, Rutgers University).

Yin, R. (2001). Estudo de caso - planejamento e métodos.Porto Alegre: Bookman. 